\title{
MH370 Controlled Eastward Veering and Descent After the 6th Arc
}

Vincent Lyne ( $\nabla$ vincent.lyne@utas.edu.au )

Retired Scientist https://orcid.org/0000-0002-7718-4050

\section{Research Article}

Keywords: Burst Frequency Offset, Burst Timing Offset, MH370, Doppler Shift

Posted Date: December 27th, 2021

DOI: https://doi.org/10.21203/rs.3.rs-962332/v2

License: (c) (i) This work is licensed under a Creative Commons Attribution 4.0 International License. Read Full License 


\title{
MH370 Controlled Eastward Veering and Descent After the $6^{\text {th }}$ Arc
}

\author{
Vincent Lyne ${ }^{1^{*}}$
}

\author{
1 Retired Scientist. Hobart. Tasmania. Australia \\ * Correspondence: Vincent.lyne@utas.edu.au (Note: UTas is not to be affiliated with this \\ article)
}

\begin{abstract}
Past expert analyses of communication signals from missing Malaysian Airlines MH370 reconciled Burst Frequency Offset (BFO) errors up to the $6^{\text {th }}$ of 7 arcs for a southerly track. After the $6^{\text {th }}$ arc, the Satellite Data Unit (SDU) power-up or reboot resulted in settling errors in the last two data points that were ignored (first search) and later bounded (second search). For the second search, investigators invoked a high-speed vertical descent to account for BFO errors for the south track fuel-starved scenario. Two searches disappointingly failed to find the implied violent-crash site. We report that interpretations were flawed in suggesting the plane dived vertically, as investigators did not recognize that BFO extrapolations implicitly implied mathematically that the plane was also cruising along the south track, but with no fuel. Our reanalysis used the "Penang Longitude" (PL) theory that predicted a similar southerly track to the $6^{\text {th }}$ arc, and that MH370 subsequently veered eastwards and descended. Doppler Shifts from vertical motions were replaced with plausible horizontal veering and declination of a high-speed aircraft. Veering predicted by the PL theory plus controlled descent plausibly accounts for nominal $7^{\text {th }}$ arc BFO discrepancies for the warmreboot scenario. We conclude that the fuel-starvation scenario analyses wrongly implied a vertical high-speed crash that ignored the impossible implicit southerly cruise, with no fuel, assumption. Instead, MH370 was piloted to a precise glide landing under power, east of the $7^{\text {th }}$ arc.
\end{abstract}

Keywords: Burst Frequency Offset, Burst Timing Offset, MH370, Doppler Shift

\section{Introduction}

Malaysian Airlines MH370, a Boeing 777-200ER equipped with the Inmarsat Classic Aero system, has not been found since it went missing on the $8^{\text {th }}$ of March 2014 with 239 people on board [1]. Inmarsat engineers identified regular monitoring "Log-on Interrogation" communications after each hour of inactivity, and two phases of specific logon requests from the aircraft near 18:25 and 00:19 UTC [2]. Detailed complex analyses of the Burst Timing Offset (BTO - distance-based measurement) and the Burst Frequency Offset (BFO - relative speed-based measurement) from these communications resulted in seven BTO global arcs 
along which the aircraft was located at different times, centred around the Inmarsat satellite located nominally above $0.5^{\circ} \mathrm{N}$ and $64.5^{\circ} \mathrm{E}$ [2].

Reconstructed potential flight paths, using the arc timings and BFO-estimated speeds/directions, generally supported a persistent southerly track down to the $6^{\text {th }}$ arc $[2,3]$. At the $7^{\text {th }}$ arc, anomalies in BFO remained after extrapolation of the BFO predicted from a good statistical fit to previous BFOs [3] and resolution of a wide variety of potential error sources [4]. Errors from the power-up settling anomalies from the Satellite Data Unit (SDU) were also bounded but discrepancies remained between a predicted BFO of $260 \mathrm{~Hz}$ and nominal observed BFOs of $182 \mathrm{~Hz}$ and $-2 \mathrm{~Hz}$ respectively at the last two communications 8 seconds apart at the $7^{\text {th }}$ arc [4]. Hypotheses on whether the SDU was started up from a power-off-on engine flame-out event (Hypothesis 1 - fuel-starvation scenario, long cold-start settling behaviour) or a warm reboot electronic event (Hypothesis 2 - electronic switching, short reboot settling behaviour) led to an extended BFO range error, and an extreme range which considered BFO noise [4]. The extreme range resulted in unrealistic descent rates, so midpoint values were used to determine that, if the southerly track continued to the $7^{\text {th }}$ arc, anomalies could only be resolved from up-down motions, unaccounted for by the SDU which only compensated horizontal motions. This led Holland [4] to generally conclude that, discounting the unrealistic extreme range (primarily from the flame-out Hypothesis 1), a 0.68 $\mathrm{g}$ ( $\mathrm{g}$ is Earth's surface gravitation acceleration constant) acceleration took place during the 8 seconds leading to a nominal high-speed descent of 10,800 fpm (feet per minute). These conclusions resulted in probable search locations of MH370 within bounds along the $7^{\text {th }}$ arc which were supported by highly promising drift model analyses of recovered debris [5]. However, extensive, and extended, searches around these bounded locations along with previous aerial searches and satellite searches, were unsuccessful [1].

In early 2021, the fuel starvation theory which guided previous searches was challenged by the "Penang Longitude" (PL) theory [6] which not only reconciled the drift model analyses but also reconciled the pilot's home simulator tracks, satellite anomalies and hydroacoustic sounds heard at listening stations at Perth Canyon [7], Cape Leeuwin and Diego Garcia [8]; which were all abandoned previously as they could not be reconciled with a crash site along the $7^{\text {th }}$ arc. The theory was predicated on the notion that there is one precise location for MH370, namely where the $33^{\circ} \mathrm{S}$ latitude intersects the longitude of Penang, where all evidence appears to plausibly intersect at an ultra-deep hole. The theory of a piloted glide landing was supported by expert investigations of debris damage by Vance [9] who has quietly suffered unfair unsubstantiated criticism of his excellent careful work. The explanation for what happened between the last two communications at the $7^{\text {th }}$ arc may critically determine whether this theory is more plausible than the failed fuel-starvation theory.

As shown in Figure 1, the southerly track of MH370 approximately concords with this theory's intuitive explanation that the track taken was to stay outside of the western boundary of the Jindalee Over-the-Horizon Radar Network (JORN) from the Laverton station in Western Australia [10]. Note that the track shown in Figure 1 was changed from the original track outside JORN [6] by moving the southerly track to intersect the $6^{\text {th }}$ arc at a bearing of about $6.7^{\circ}$ east from due south. This change was made to align more closely with the estimated southerly track from the reconciled BFO analyses down to the $6^{\text {th }}$ arc. We assume for this study that the aircraft is flying southerly at the $6^{\text {th }}$ arc, as the primary interest is what caused the BFO changes after the $6^{\text {th }}$ arc at the last two communications at the $7^{\text {th }}$ arc: the first at 00:19:29 UTC, and the second at 00:19:37 UTC.

The $7^{\text {th }}$ arc' BFO evidence and analyses to date suggesting an uncontrolled violent crash are at odds with this theory's prediction of a meticulously planned precise piloted powered glid landing, which was also suggested independently from the detailed careful interpretations 
of debris "witness marks" by Vance [9] -implying that there was little or no randomness in the plan. Hence, our aim is to test whether alternate plausible explanations of the $7^{\text {th }}$ arc BFOs are possible and in keeping with this theory's prediction of an eastward turn of MH370 once past the southern end of the JORN range located approximately at $32^{\circ} \mathrm{S}$, with the actual turn taking place near $33^{\circ} \mathrm{S}$ latitude, at a waypoint, ultimately towards a secret deep hole.

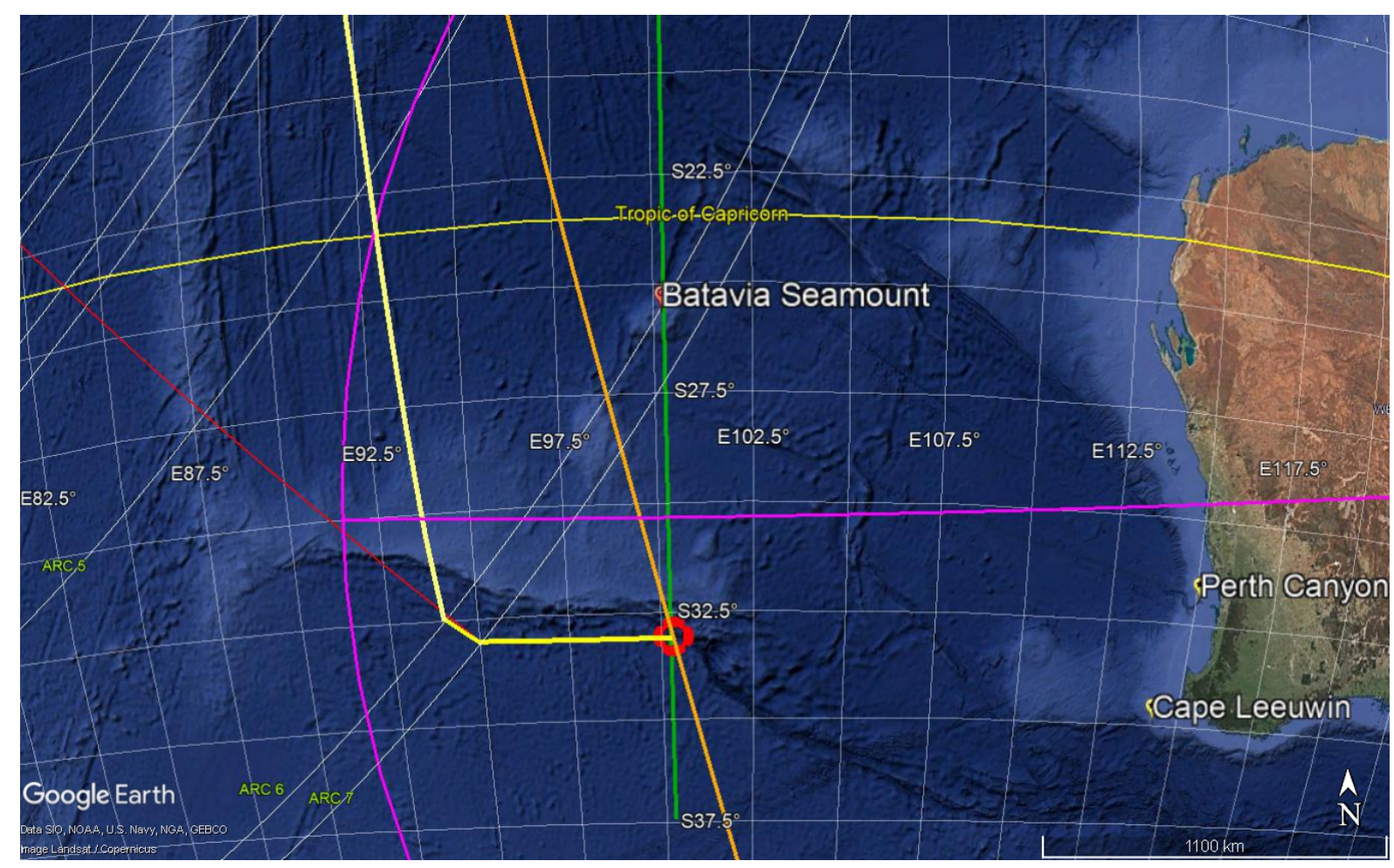

Figure 1 Main map features of the BFO analyses. The white curves are the 7 arcs. The purple curve is the Jindalee Over the Horizon Radar Network (JORN) range, and the purple line marks the southern limit of the range. One postulated example flight path of the Penang Longitude theory is in yellow showing an approximately southerly track that intersects the $6^{\text {th }}$ arc (ARC 6) at $94^{\circ} \mathrm{E}$, then veers to $33^{\circ} \mathrm{S}, 95^{\circ} \mathrm{E}$ at the $7^{\text {th }}$ arc (ARC 7), and then proceeds to the postulated Penang Location (red circle) intersected by the Penang longitude (green vertical line). Note that this track is a modification of the original predicted southerly track outside the JORN range; this version cuts the southwest corner of JORN at a bearing of $6.7^{\circ}$ east of a southerly track. Note for later purposes, the close alignment of the track running between the $6^{\text {th }}$ and $7^{\text {th }}$ arcs with the bearing to the satellite. The orange line running northeast is one of the simulation tracks from the pilot's home simulator [1] which passes precisely over the Penang Location. The depth at the Penang Location hole is just under $6000 \mathrm{~m}$ according to Google Earth Pro.

Much has been written about the BFO analyses, and since there is general acceptance of BFO interpretations of a southerly track up to the $6^{\text {th }}$ arc, our focus, as per Holland [4], will be on the change between the two final $7^{\text {th }}$ arc BFOs; in particular on alternate explanations for anomalies arising from Holland's calculated nominal range for the observed BFOs [4]. We focus on anomalies for the "warm start" Hypothesis 2, rather the extreme anomalies for Hypothesis 1 where fuel starvation leads to engine flame-out followed by a restart of the SDU using power from the Auxiliary Power Unit (APU) [4]. The "warm start" refers to a warm reboot from a power switching rather than a fuel-starved power outage, which is more compatible with the PL theory's prediction that the aircraft was undergoing preparations for its descent phase. In any case, the precedence for this power glitch assumption was established by a previous such event (at 18:25 UTC) when the aircraft clearly did not run out of fuel.

\section{Method}


The main difference between our proposed analysis and past analyses is that we allow the aircraft track to vary, and to veer eastwards from a southerly track at the $6^{\text {th }}$ arc for a descent along the $33^{\circ} \mathrm{S}$ latitude to a destination at the PL location. This contrasts with the fuelstarvation theory which required the aircraft to maintain its southerly track - that was assumed to be compensated for by the SDU unit [2]. The other difference is that the up-down motions analysed by Holland [4] are implicitly incorporated into a flight descent model where the aircraft descends at a declination angle to the horizontal plane. For our analyses, we also ignore the $6.7^{\circ}$ difference between the predicted track (Figure 1) and a southerly track required by the BFO analyses up to the $6^{\text {th }}$ arc. We assume that the actual track is southerly at the $6^{\text {th }}$ arc and only analyse differences from this at the last two communications at the $7^{\text {th }}$ arc.

These changes are incorporated into the standard Doppler Shift model of equation (1) that defines the frequency change observed from a moving electromagnet source:

$$
F_{o}=\frac{C * F}{(C-V)}
$$

Where: speeds are in kilometres per hour $(\mathrm{kph})$; frequencies are in $\mathrm{Hertz}(\mathrm{Hz}) ; \mathrm{C}$ is the speed of light $(1.079 \mathrm{e}+9 \mathrm{kph}) ; V$ is the speed component of the aircraft velocity vector $(\mathrm{kph})$ that is aligned with the vector from the aircraft to the Inmarsat satellite (positive towards the satellite); $F$ is the uplink frequency from the aircraft to the satellite $(1646.6525 \mathrm{MHz})$; and $F_{o}$ is the received Doppler-shifted frequency (assuming no compensation was applied).

The magnitude of velocity $V$ was calculated from the aircraft track, heading and elevation to the Inmarsat satellite, and an assumed declination angle according to equation (2).

$$
V=S * \cos \left(\theta_{e}-\theta_{d}\right) * \cos \left(\theta_{s}-\theta_{a}\right)
$$

Where: heading and track angles are measured clockwise from North; $S$ is the ground speed of the aircraft; $\theta_{e}$ is the aircraft to satellite elevation angle from horizontal (positive and set to $38.8^{\circ}$ for the $7^{\text {th }}$ arc following Holland [4]); $\theta_{d}$ is the aircraft declination angle (positive for descent); and $\theta_{s}$ and $\theta_{a}$ are heading angles at ground level for the satellite and aircraft respectively (so $0^{\circ}$ is a track to the North and $180^{\circ}$ is a South track).

The calculated velocity magnitude $(V)$ is used in equation (1) following the appropriate sign conventions. The first cosine term in equation (2) accounts for the satellite elevation angle modulated by the aircraft declination, so that when these angles are the same the frequency offset is at an absolute maximum as the aircraft is proceeding directly to the satellite or away from it. Likewise, for the alignment of the satellite and aircraft headings in the second cosine term. The two equations represent the model we used to calculate expected uncompensated BFOs for various combinations of aircraft track angle $\left(\theta_{a}\right)$ and declination angle $\left(\theta_{d}\right)$. Other parameters were fixed as listed in Table 1.

Table 1 Ancillary parameters for the BFO calculations.

\begin{tabular}{|c|l|l|}
\hline Parameter & \multicolumn{1}{|c|}{ Description } & \multicolumn{1}{c|}{ Value } \\
\hline Inmarsat Satellite Location [2] & $\begin{array}{l}\text { Ground projected location of the } \\
\text { Inmarsat Satellite at 00:19 UTC }\end{array}$ & $0.5^{\circ} \mathrm{N}, 64.475^{\circ} \mathrm{E}$ \\
\hline Inmarsat Satellite Elevation [4] & $\begin{array}{l}\text { Elevation angle from the aircraft } \\
\text { location to the satellite }\end{array}$ & $38.8^{\circ}$ \\
\hline
\end{tabular}




\begin{tabular}{|c|c|c|}
\hline $\begin{array}{l}\text { Aircraft Location and heading } \\
\text { at } 7^{\text {th }} \text { arc }\end{array}$ & Estimated by Ashton et al. (2015) [2] & $\begin{array}{l}\text { Location: } 34.7^{\circ} \mathrm{S}, 93.0^{\circ} \mathrm{E} \\
\text { Heading: } 323.98^{\circ} \text { from North }\end{array}$ \\
\hline Aircraft Location at $7^{\text {th }}$ arc & According to the PL theory & $\begin{array}{l}\text { Location: } 33.0^{\circ} \mathrm{S}, 95.0^{\circ} \mathrm{E} \\
\text { Heading: } 320.99^{\circ}\end{array}$ \\
\hline Aircraft speed at $7^{\text {th }}$ arc & In kph & $829 \mathrm{kph}[2]$ \\
\hline $\begin{array}{l}\text { First BFO at } 7^{\text {th }} \text { arc: at } 00: 19: 29 \\
\text { UTC [4] }\end{array}$ & $\begin{array}{l}\begin{array}{l}\text { Predicted for south track and } \\
\text { observed }\end{array} \\
\end{array}$ & $\begin{array}{l}\text { Predicted } 260 \mathrm{~Hz} \\
\text { Observed } 182 \mathrm{~Hz}\end{array}$ \\
\hline $\begin{array}{l}\text { Second BFO at } 7^{\text {th }} \text { arc: at } \\
00: 19: 37 \text { UTC [4] }\end{array}$ & $\begin{array}{l}\begin{array}{l}\text { Predicted for south track and } \\
\text { observed }\end{array} \\
\end{array}$ & $\begin{array}{l}\text { Predicted } 260 \mathrm{~Hz} \\
\text { Observed } \quad-2 \mathrm{~Hz}\end{array}$ \\
\hline
\end{tabular}

Our aim with the analyses was to investigate the change of BFO between the last two $7^{\text {th }}$ arc communications. We had the choice of using the Ashton et al. (2014) [2] location (Table 1) or the PL theory location [6]. We chose the PL location since it is the focus of the analyses and the coincidence of the integer latitude and longitude crossing $\left(33.0^{\circ} \mathrm{S}, 95.0^{\circ} \mathrm{E}\right)$ at the $7^{\text {th }}$ arc seemed remarkable and was predicted by the PL theory as a waypoint (Figure 1).

The BFO error at the two times in Table 1represent the difference between predicted BFO for a frequency-compensated south track and measured SDU-frequency-compensated BFO. If the south track was correct, the SDU frequency compensation and predicted frequency compensation would match. In other words, a match of horizontal-motion-compensated BFOs would imply that the aircraft was indeed on a horizontal southerly track - as witnessed for arcs prior to the $7^{\text {th }}$ arc. The $7^{\text {th }}$ arc mismatch was interpreted by previous investigators as due to vertical motions not compensated by the SDU - leading to the high-speed descent conclusion [4]. By contrast, the PL theory suggests that the SDU was compensating for an eastward-veered track which would lead to a mismatch of frequency compensations between predicted and observed, in addition to any uncompensated vertical motions. It is this mismatch which we investigate using equations (1) and (2) to predict BFO errors expected between the south track and an assumed eastward-veered track (with positive values implying the aircraft was tracking more rapidly away from the satellite).

\section{Results}

For a level flight (no declination), the BFO difference between the south track ( $180^{\circ}$ track) and other track angles are shown in Figure 2. At the south track reference, the difference is zero and increases as the track veers eastward towards angles smaller than $180^{\circ}$. Westward veering would lead to BFO changes of the wrong sign (increasing towards the satellite), and hence discounted.

The $80 \mathrm{~Hz}$ dashed line marks the approximate location of the mismatch at the first $7^{\text {th }}$ arc communication $(80 \mathrm{~Hz}=$ Predicted $260 \mathrm{~Hz}$ - Observed approximate $180 \mathrm{~Hz})$. The mismatch would require a veering eastward of less than $8^{\circ}$ from the south track, and it is in the right direction. This small angle change suggests also that the aircraft may have started to veer from a southerly track just before the first of the communications at the $7^{\text {th }}$ arc. Implying that the path from the $6^{\text {th }}$ arc to that point is less veered than suggested by the general PL path in Figure 1.

The second communication mismatch was nearly $260 \mathrm{~Hz}$ and the maximum veering (where the aircraft track is aligned to the satellite direction but moving away from the satellite) occurs at about $141^{\circ}$ heading giving a value of $220 \mathrm{~Hz}$. Implying that during the 8 seconds between communications, the aircraft would need to veer 39 degrees or at a rate of 4.875 degrees per second - compared to nominal aircraft turning rates of about 3 degrees per second. 
Even though the bulk of the BFO mismatch is explainable, a significant amount $(40 \mathrm{~Hz})$ is not explainable by a veering model alone. Note that the heading required for maximum BFO is closely aligned coincidentally with the bearing to the satellite as noted in Figure 1 . The totality of the required veering from the $6^{\text {th }}$ arc is well matched in explaining much of the nominal BFO change.

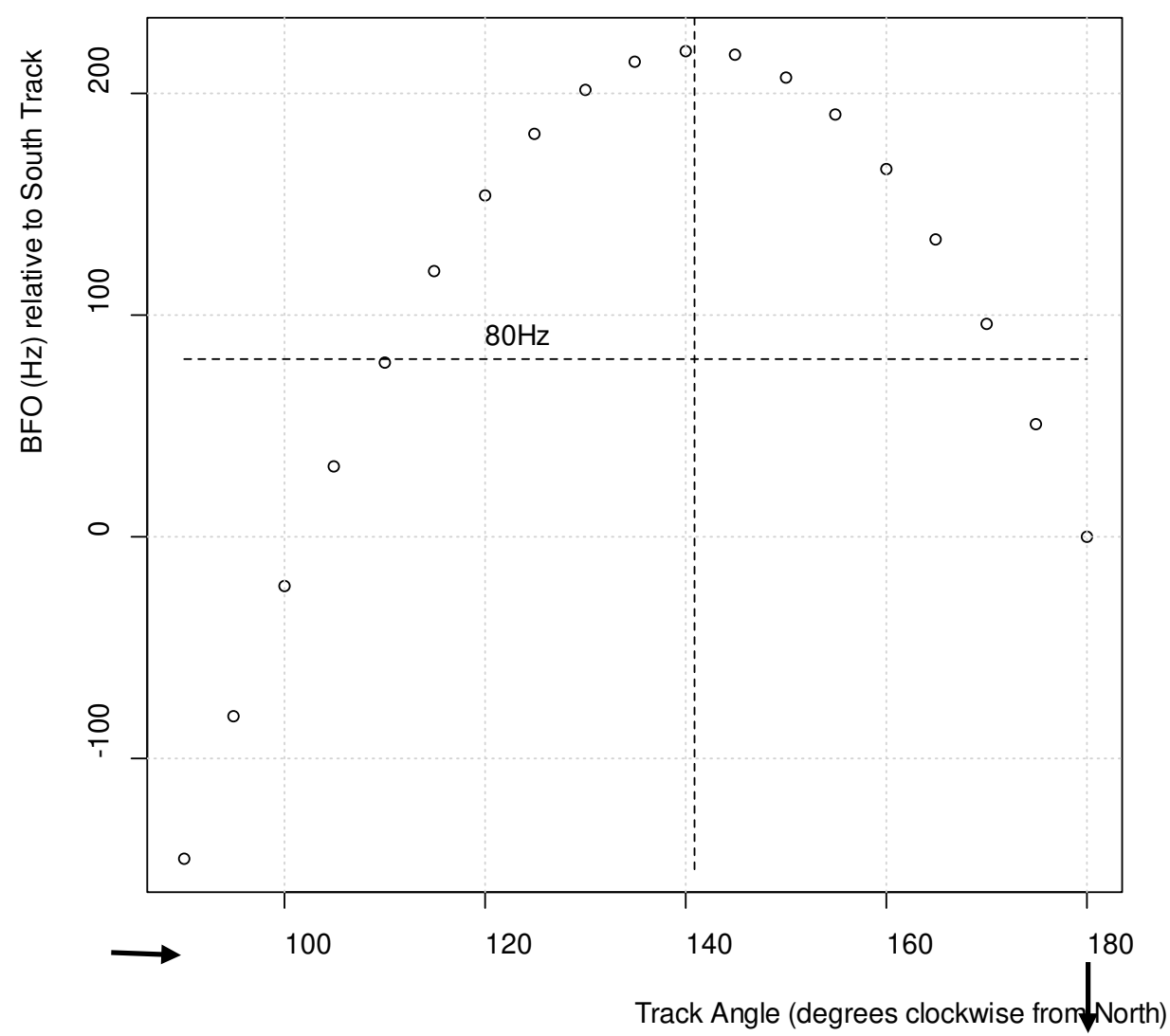

Figure 2 Variation of $\mathrm{BFO}(\mathrm{Hz})$ relative to a south track $\left(180^{\circ}\right.$ track) with track angle measured in degrees clockwise from North. The dashed vertical line marks the approximate track which aligns with the aircraft to satellite direction. Note the directionality of the BFO change is such that if the aircraft is moving faster away from the satellite (as it will when it veers towards $141^{\circ}$ heading), the SDU will compensate for the reducing frequency. So, a positive error as displayed means the error is defined as Predicted (BFO at $180^{\circ}$ ) - Measured (BFO at Track Angle).

For the indicated track range, the rate of decline of BFO with track angle as shown in Figure 3 is greatest at $180^{\circ}$, and zero when the track is aligned with the direction to the satellite. In other words, eastward veering produces the greatest BFO change rate at the south track, and the change with track angle is minimal when the track is aligned with the satellite direction. At the south track, one degree of track veering to the east, with no up-down motion, produces $10 \mathrm{~Hz}$ BFO decrease - a change that requires $588 \mathrm{fpm}$ downward motion according to Holland's model. 


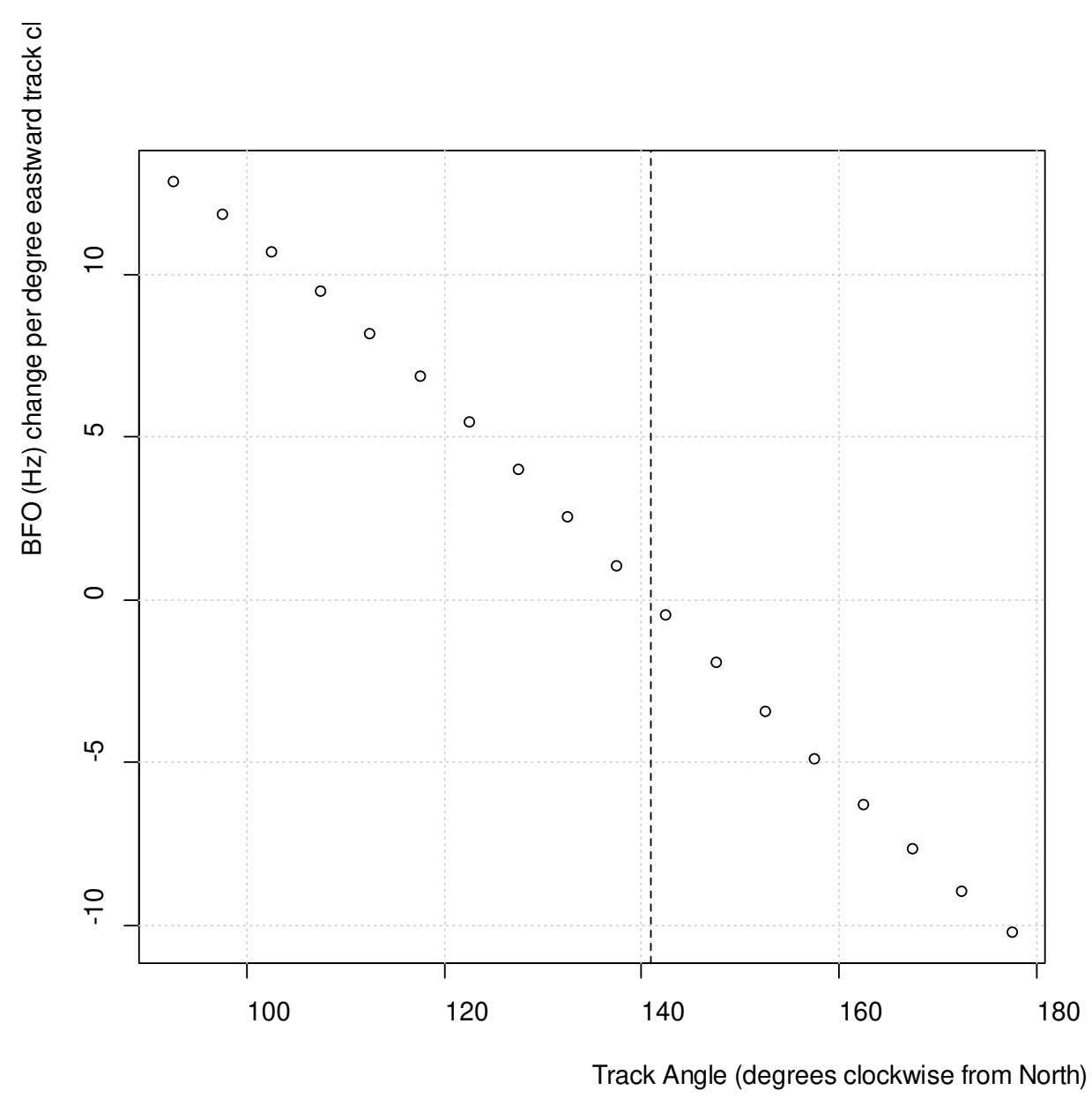

Figure 3 Variation of BFO change per degree of track angle change. The dashed vertical line marks the approximate track which aligns with the aircraft to satellite direction.

With declination included the range of BFO variation with track angle and declination angles are as contoured in Figure 4. For reference, the predicted 10,800 fpm high-speed descent of Holland corresponds to about $13.78^{\circ}$ declination in Figure 2, with a maximum BFO mismatch of over $350 \mathrm{~Hz}$ explainable - compared to about $184 \mathrm{~Hz}$ for the up-down Holland model. The $260 \mathrm{~Hz}$ mismatch is now explainable using the approximate $250 \mathrm{~Hz}$ contour in Figure 4 , which suggests a minimum declination required of about $3^{\circ}$. The contour displays the balance between veering and declination required to achieve a BFO mismatch. This angle is within normal aircraft descent angles near the satellite-aligned track, and achievable within the 8 second window. The minimum declination required also suggests that the aircraft was descending at the last signal.

At the south track, changes are near-maximal with veering and declination (Figure 4), whereas at the satellite-aligned track, declination is mainly responsible for changes. Of interest to note is that the veering to an easterly track was not achieved by the time of the second communication, implying that, if our interpretations are correct, the aircraft was still veering towards the final east track. The sensitivity to track change is also minimal at about $141^{\circ}$ as shown in Figure 3, implying that the estimate of track angle at this point is not highly sensitive to BFO change. But there is high sensitivity in the opposite direction as the track veers further eastward, but we are unable to resolve this due to the lack of communications beyond the $7^{\text {th }}$ arc. 


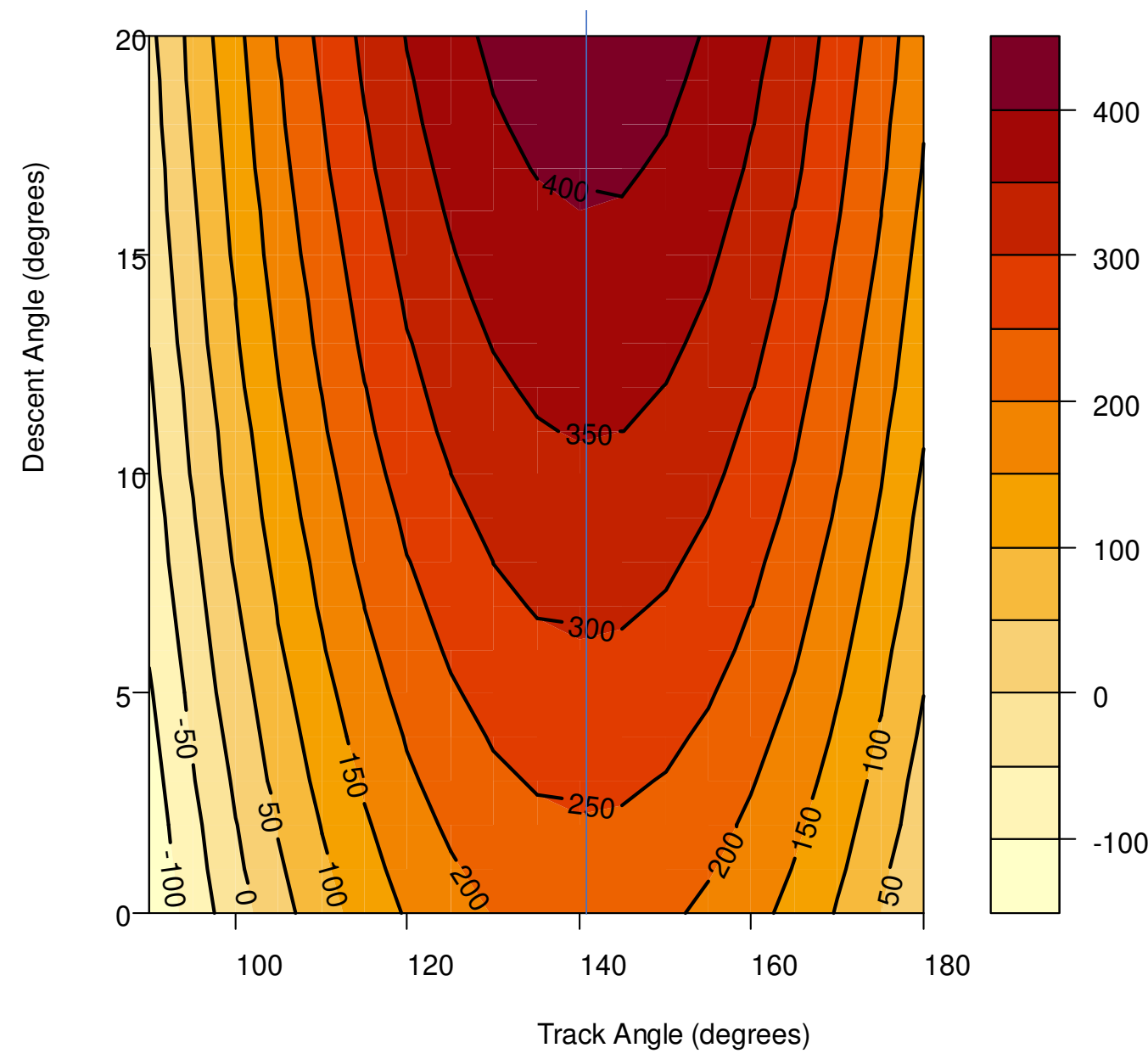

Figure 4 Contoured variation of $\mathrm{BFO}(\mathrm{Hz})$ with track angle and declination angle. The vertical line marks the approximate track which aligns with the aircraft to satellite direction.

\section{Discussion}

Brilliant past technical analyses of complex BFO changes deciphered from satellite and phone communications provided much needed clarification of MH370's southerly track to the southern Indian Ocean up to the $6^{\text {th }}$ arc. However, later analyses of perplexing added BFO changes at the last two communications were apparently resolved through uncompensated updown motions as there was no reason to assume a change from the fuel-starvation-theory southerly track. The south track was extrapolated to the $7^{\text {th }}$ arc and vertical velocity shifts required to explain the remaining BFO changes led to the high-speed descent scenario and an assumed unobserved violent impact. Instead, the damage found on the recovered flaperon (and the limited amount of debris) was convincingly demonstrated, by finite-element simulations conducted by the MH370-Captio group [11], as well as careful detailed expert investigations by Vance [9], as most likely due to a piloted glided landing, and incompatible with a highspeed nosedive that would have crumpled the leading-edge nose [11] and obliterated the plane into many pieces within the blink of an eye [9]. 
Whilst the glided landing scenario is now more plausible, the notion that MH370 was in a vertical high-speed dive at the $7^{\text {th }}$ arc is still prevalent in public media [12] and in acrimonius criticism of alternative theories. A glided landing at the $7^{\text {th }}$ arc is also clearly at odds with the suggested uncontrolled high-speed descent demanded to explain the BFO changes. The failure of two comprehensive searches predicated on the theory of fuel-starvation-at-the- $7^{\text {th }}$-arc has stymied plans for another search. The final location of MH370 must also explain all plausible evidence, one of which is the BFO interpretations at the $7^{\text {th }}$ arc. No theory has succeeded in meeting these requirements till now.

Despite the reconciliation of all other evidence by the PL theory there were no previous analyses to support the predictions of this theory that MH370 veered eastward at the $7^{\text {th }}$ arc to follow an easterly track at $33^{\circ} \mathrm{S}$ latitude. The theory is specific about when such a change should occur in relation to the JORN network range. The observation that such a change could be underway at $33^{\circ} \mathrm{S}, 95^{\circ} \mathrm{E}$, which is on the $7^{\text {th }}$ arc is either a remarkable coincidence, or a planned waypoint for a track change as predicted by the PL theory. These observations and the failures of the fuel-starvation theory led us to re-examine interpretations of the final BFOs from MH370.

Results of our veering model suggests that the first $\mathrm{BFO}$ is explainable with less than $8^{\circ}$ eastward veering from the south track at the $7^{\text {th }}$ arc where BFO changes are sensitive to track change. Reconciliation of the second BFO required a track change to about $141^{\circ}$ heading (approximate south-eastward track), a declination angle of at least $3^{\circ}$, but with an aggressive turn rate. These parameters seem more reasonable and plausible, than an unverified highspeed descent. This disparity (of a small veering change and declination versus high-speed descent) is understandable as the Doppler Shift is due to the speed change in the direction of the satellite, regardless of whether it is from horizontal veering of an aircraft flying at high speed, or a presumed sudden diving down at high speed (whilst also maintaining its south track). But the two different interpretations give two very different and incompatible landing scenarios.

To resolve this, we suggest respectfully that past investigators forgot that the extrapolation of the BFO curve along the south track to the $7^{\text {th }}$ arc implied that the plane was implicitly required to be flying south at its cruise speed; in addition to undergoing the high-speed vertical dive, with no fuel left. However, the official narrative for this scenario in media stories, which is inconsistent with the mathematics, is that the plane simply ran out of fuel and accelerated into a high-speed vertical dive. The mathematical narrative for this scenario is that the plane ran out of fuel but was still able to magically continue flying at cruise speed along the south track, and within 8 seconds also experienced an added (to the cruise speed) high-speed vertical dive of about 10,800 fpm. The two narratives are incompatible, implausible, and disappointing. The first does not explain the BFO changes, and the latter is clearly impossible. It's an honest mistake, that we should not unduly dwell upon, brought about by the complex assumptions in interpreting the BFO discrepancies. If we are to resume the search for MH370 we need to stop the misinformation on what happened at the second arc and show respect to investigators such as Vance [9] who have articulated a piloted glided landing scenario based on well-founded objective investigations of debris evidence.

Whilst details of the tracks predicted for the $6^{\text {th }}$ arc and the first of the communications at the $7^{\text {th }}$ arc aren't precise, results of the veering analyses can explain the $7^{\text {th }}$ arc BFO changes. The analyses suggest that the turn to an easterly track was not complete and changes to the aircraft's flight were still underway. The overall changes in flight track align closely with the general predictions of the PL theory. We also note that the short disturbance to power to the SDU after the $6^{\text {th }}$ arc (Hypothesis 2) may have been from preparation for the descent, predicted by the analyses to be underway by the end of the $7^{\text {th }}$ arc. Whereas the fuel-starvation theory 
assumes the power-up was from engines flaming out and the cold SDU restarting sometime later - the extreme Hypothesis 1 scenario.

Simply put, what we have demonstrated is that the Doppler Shifts observed at the $7^{\text {th }}$ arc were not from implausible extreme combined vertical and horizontal motions, but were instead due to plausible horizontal veering of an aircraft travelling at high speed. Past analyses were hamstrung by wayward interpretations of complex analyses, by the south track fuelstarvation theory, and understandable lack of consideration of alternate scenarios which could have aided in optimizing the search strategy [13]. Still, given the uncertainties and disappointments to date in finding MH370, we caution that this and other predictions of the PL theory need to be subjected to further critical evaluation despite the theory being the only one that reconciles most if not all plausible evidence, which now includes the BFO changes at the $7^{\text {th }}$ arc. This study should however be judged by its merits in explaining the BFO signals at the $7^{\text {th }}$ arc.

\section{Conclusions}

The baffling BFO changes at the final two communications from MH370 at the $7^{\text {th }}$ arc are more plausibly due to the aircraft veering eastward and in a controlled descent, as opposed to an uncontrolled high-speed vertical dive. These interpretations were predicted by the Penang Longitude theory which also predicts that MH370 proceeded to a precise piloted glide landing where the $33^{\circ} \mathrm{S}$ latitude intersects the longitude of Penang at an ultra-deep hole. These revised interpretations refute the high-speed descent demanded by the fuel-starvation southerly-track theory as that conclusion was based on incorrect interpretations of the BFO assumptions and analyses. We can state with greater certainty that MH370 veered eastward and was descending after its last known communication.

\section{Acknowledgements}

Many keen scientists indirectly contributed to this study which would not have been possible without their remarkable technical detective work on diverse aspects of finding MH370. We are all deeply indebted to all the brave folks who took part in the search for MH370 in one of the most inhospitable, but ecologically unique, ocean environments on the planet. Despite not finding MH370 your work has contributed to excluding vast areas of the ocean from further searches, and hopefully restored faith in humanity's kindness to those who lost loved ones. I am particularly indebted to Larry Vance for his independent expert thorough investigations of debris damage; a quiet voice of reason lost in the cacophony of contrived misinformation.

1. ATSB. The Operational Search for MH370; Canberra. Australia., 2017; p. 440pp.

2. Ashton, C.; Shuster Bruce, A.; Colledge, G.; Dickinson, M. The Search for MH370. Journal of Navigation 2014, 68, 1-22, doi:10.1017/s037346331400068x.

3. Davey, S.; Gordon, N.; Holland, I.; Rutten, M.; Williams, J. Bayesian Methods in the Search for MH370; Springer Singapore: 2016.

4. Holland, I.D. MH370 burst frequency offset analysis and implications on descent rate at end of flight. IEEE Aerospace and Electronic Systems Magazine 2018, 33, 24-33, doi:10.1109/maes.2018.170048.

5. Griffin, D.A.; Oke, P.R.; Jones, E.M. The search for MH370 and ocean surface driftPart II; CSIRO Oceans and Atmosphere: Hobart. Australia, 2017; p. 26pp. 
6. Lyne, V.; Lyne, M. Unravelled cryptic pathways of MH370-goodbye and travel-path secrecy reveals landing details and precise location. Researchgate 2021, 36pp., doi:10.13140/RG.2.2.12116.94084/1.

7. Butler, D. Sound clue in hunt for MH370. Nature 2014, 510, 199-200.

8. Kadri, U. Effect of sea-bottom elasticity on the propagation of acoustic-gravity waves from impacting objects. Sci Rep 2019, 9, 912, doi:10.1038/s41598-018-37626-z.

9. Vance, L. MH370 Mystery Solved; Group of Three Publishing: 2018.

10. Wikipedia. Jindalee Operational Radar Network. Available online: https://en.wikipedia.org/wiki/Jindalee_Operational_Radar_Network (accessed on March 2021).

11. MH370-Captio. MH370: Was Air Traffic Control deliberately misled? Available online: https://www.youtube.com/watch?v=Qk1CxO9XGyQ (accessed on

12. Gregersen, E. Malaysia Airlines flight 370 disappearance. https://www.britannica.com/event/Malaysia-Airlines-flight-370-disappearance 2021.

13. Wikipedia. Scenario optimization. Available online: https://en.wikipedia.org/wiki/Scenario_optimization (accessed on October 2021). 